\title{
The frequency of nucleophosmin I gene mutation in newly diagnosed patients of acute myeloid leukemia
}

\begin{abstract}
Introduction: Nucleophosmin1 (NPM1) gene mutation is the most frequently occurring gene mutation in acute myeloid leukemia. This mutation is associated with good prognosis. AML patients should be screened for the NPM1 gene mutation to identify patients with good response to chemotherapy. Its association with FLT3-ITD mutation is related to poor outcome. B: To evaluate the frequency of NPM1 gene mutation in newly diagnosed patients of AML.
\end{abstract}

Study design: Cross sectional study.

Settings and duration: Armed Forces Institute of Pathology (AFIP), Rawalpindi from $1^{\text {st }}$ September 2014 to $30^{\text {th }}$ June 2015.

Patients and duration: Patients of age between 5 to 85 years and both gender diagnosed with AML at AFIP were included. After informed consent $2 \mathrm{ml}$ bone marrow samples were collected from patients. RNA was extracted and complimentary DNA was synthesized using reverse transcriptase. Polymerase chain reaction (PCR) was done using Amplification refractory mutation system methodology. PCR products were visualized by electrophoresis on Poly Acryl Amide Gel.

Results: Out of 95 AML patients34 (35.7\%) were positive for NPM1 gene mutation with a median age of 47 years. 80 were males while 15 were females. Out of 34 NPM1 positive patients $14(26.9 \%)$ were AML M2 subtype, 13 patients $(38.2 \%)$ were AML M4, $03(8.82 \%)$ were AML 3 while there were $4(11.7 \%)$ cases of AML M5.

Conclusion: NPM1 gene mutation is quite frequent in our patients of AML and its identification will help identify patients with good response to chemotherapy.

Keywords: acute myeloid leukemia, nucleophosmin 1 gene mutation, NPM1 mutation
Volume 6 Issue 5 - 2018

\author{
Samrah Shahid, Saleem Ahmed Khan, Maliha \\ Saad, Muhammad Ayyub, Ch Altaf Hussain, \\ Hamid Saeed Malik, Parvez Ahmed \\ Department of Haematology,Armed Forces Institute of \\ Pathology, Pakistan
}

Correspondence: Samrah Shahid, Department of Haematology, Armed Forces Institute of Pathology, CMH Road, Rawalpindi, Pakistan, Tel 00923325447243,

Email samrahshahid22@gmail.com

Received: August 03, 2018| Published: October 23, 2018

\section{Introduction}

Acute myeloid leukemia (AML) is a heterogeneous group of disorders characterized by a rapid increase in the number of immature myeloid cells in bone marrow and peripheral blood. This overproduction of immature myeloid blasts decreases overall efficiency of the hematopoietic system resulting in anemia, thrombocytopenia with or without increase in the total leucocyte count. ${ }^{1}$ Several genetic mutations, chromosomal translocations and gene rearrangements are involved in the pathogenesis of leukemia. ${ }^{2}$ The cytogenetic analysis at the time of diagnosis is the most important prognostic factor in AML.

Nucleophosmin 1 (NPM 1) gene mutation is the most frequently occurring gene mutation in AML accounting for about $40-50 \%$ of patients. ${ }^{3}$ It is a nucleocytoplasmic shuttling protein that shows highly restricted nucleotide localization. It is involved in several activities at cellular level such as ribosomal biosynthesis, maintenance of genome stability and molecular chaperon functions. ${ }^{4}$ Abnormal expression of NPM 1 gene may lead to the oncogenesis of AML as it is a partner in several tumor associated chromosomal translocations. It causes inactivation of tumor suppressor gene p53. Chromosomal aberrations involving NPM 1 were found in patients with nonHodgkin lymphoma, acute promyelocytic leukemia, myelodysplastic syndrome and AML. It has been found in the cytoplasm of AML patients with variable prevalence and proven to have prognostic significances. These alterations seem to identify patients with better response to therapy hence their study will help identify patients with good prognosis avoiding unnecessary bone marrow transplantation after first complete remission. ${ }^{5}$

NPM1 exon 12 mutations are the most frequent mutations in AML, found in approximately $35 \%$ of adult patients. Due to these mutations cytoplasmic concentrations of NPM1 (NPMc) are unusually increased in the leukemic cells. ${ }^{6}$ AML secondary to MPS and MDS are not associated with these mutations. ${ }^{7}$ NPM1 mutations usually have tetra nucleotide insertions that result in a frame shift. ${ }^{8} \mathrm{At}$ present, 55 different mutations of NPM1 have been reported in AML. The most common NPM1 mutation type A, accounting for 75 to $80 \%$ of all NPM1 mutation, is an insertion of TCTG. Mutations B and D are observed in $5 \%$ and $10 \%$ of NPM1 positive patients. ${ }^{9}$ In children mutation $\mathrm{A}$ is seen in 11 to $50 \%$ of all NPMc cases. ${ }^{10}$

Structurally, NPM has two nuclear-export signal (NES) motifs at its C-terminus and one nucleolar-localization signal (NLS). The NLS, via its nucleolar binding domains moves NPM from cytoplasm into the nucleolus. ${ }^{11}$ The Wild type form, NPM is predominantly limited to the nucleus because in this form the NLS is dominant over the weaker NES. ${ }^{12}$

The aim of this study is to find out the frequency of NPM 1 mutations in newly diagnosed AML cases so that patients with good response to chemotherapy can be prevented from more aggressive treatments. Hence, saving them from unnecessary exposure to a procedure that itself has several complications and comorbidities. 


\section{Material and method}

A total of 95 patients were included in this study. They were included after being diagnosed as case of acute myeloid leukemia on bone marrow morphology, cytochemistry and Immunophenotyping at Armed Forces Institute of Pathology, AFIP from September 2014 to June 2015. Laboratory findings (WBC count, platelet count, blast percentage, FAB subtypes etc) were recorded on a Performa of molecular studies department AFIP specifically designed for NPM1 gene mutation.

\section{Data collection procedure}

Specimen Collection: Ethical Committee approval will be taken. From each patient verbal informed consent would be obtained. Five $\mathrm{ml}$ of EDTA anti coagulated bone marrow aspiration sample will be collected from each patient.

\section{Determination of NPMI gene mutation}

After informed consent, bone marrow cells were collected from patients. RNA was extracted from the sample. Complimentary
DNA (cDNA) was synthesized from the extracted RNA by reverse transcription (Table 1).

The NPM-AN shows the primer sequence of the mutated NPM1 gene used in the study. It shows the insertion of four base pairs TCTG at position 956 to 959 of the primer sequence. A 320 base pair fragment was amplified from 1 micro liter of cDNA in a total volume of $25 \mathrm{micro}$ liter of the reaction mixture containing $10 \mathrm{pmol}$ of each primer, NPM-A and NPM-REV 6, $1 \times$ PCR buffer, $2.5 \mathrm{mmol} / \mathrm{L}$ Magnesium Chloride, 5mmol/L deoxynucleoside-5-triphosphate and $0.7 \mathrm{U}$ of Taq polymerase.

The temperature conditions of the thermal cycler (Bio Applied Thermal Cycler) were as follows:

Preheating of the mixture at $95^{\circ} \mathrm{C}$ for 7 minutes was followed by Denaturation: 35 cycles of 30 seconds at $95^{\circ} \mathrm{C}$

Annealing: 45 seconds at $67^{\circ} \mathrm{C}$ and 45 seconds at $72^{\circ} \mathrm{C}$

Extension: 7 minutes at $72^{\circ} \mathrm{C}$

Polymerase Chain Reaction products were visualized by electrophoresis on Poly Acrylamide gel (Figure 1).

Table I Primers used for ASO-RT-PCR, Semi-nested ASO-PCR, Sequencing and fragment analysis

\begin{tabular}{|c|c|c|c|c|}
\hline Name & Sequence & pcr Product (size) & & Applica \\
\hline NPM-A & 5'CCAAGAGGCTATTCAAGATCTCTCTC-3' & $\begin{array}{l}\text { NPMI-mut-A } \\
\text { I2(320bp) }\end{array}$ & ex & ASO-RT PCR NP mut A \\
\hline $\begin{array}{l}\text { N P M - } \\
\text { AN }\end{array}$ & 5'CAAGAGGCTATTCAAGATCTCTGTCTG-3' & $\begin{array}{l}\text { NPMI-mut-A } \\
\text { I2(319bp) }\end{array}$ & ex & $\begin{array}{l}\text { Semi-nested ASO-PCR NPMI-mPCR NP mut } \\
\text { A }\end{array}$ \\
\hline NM-F2 & 5'ATCAATTATGTGAAGAATTGCTTAC-3' & & & NPMI e: sequence \\
\hline
\end{tabular}

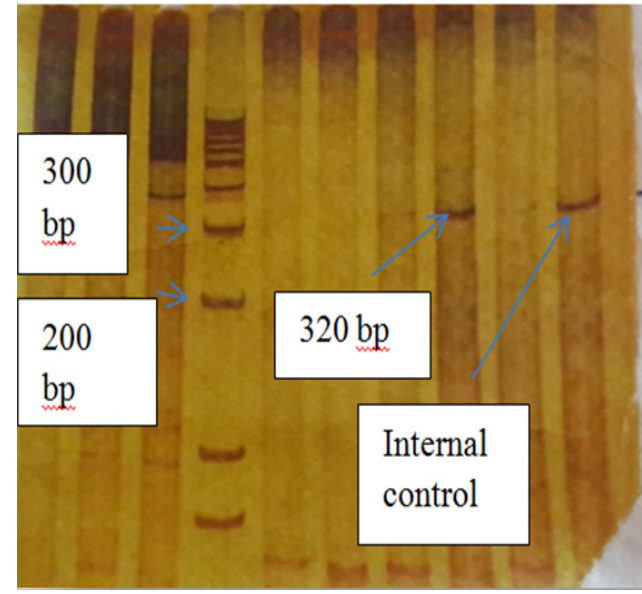

Figure I A representative polyacrylamide gel picture showing NPMI mutation screening. A positive result is shown at 320 base pairs along with the internal control.

\section{Results}

Out of 95 AML patients 34(35.7\%) were positive for NPM1 gene mutation with a $p$ value of $0.92 .80(84.2 \%)$ were males while 15 $(15.7 \%)$ were females. The data of the patients included in this study is mentioned in the Table 2

Median values and range of age, WBC count, platelet count of the positive patients are shown in Table 3. Out of 34 NPM1 positive patients 14 patients were AML M2 subtype, 13 patients were AML M4, 4 cases were AML M3 while there were 3 cases of AML M5a. Out of 7 FLT 3 positive cases 1 was positive for NPM1 mutation as well.
Percentages of NPM1 mutation was higher in females (7 out of $887.5 \%$ ) than in male patients (27 out of $8021.6 \%$ ). The mean blast count in NPM1 mutated cases was $71.98 \%$.

Table 2 Patient's data

\begin{tabular}{|c|c|c|c|c|}
\hline & & Total & $\begin{array}{l}\text { N P M I } \\
\text { negative }\end{array}$ & $\begin{array}{l}\text { N P M I } \\
\text { positive }\end{array}$ \\
\hline \multirow{2}{*}{ Gender } & Female & 15 & 8 & 7 \\
\hline & Male & 80 & 53 & 27 \\
\hline Age (Years) & $5-85$ & & & 47.5 \\
\hline \multicolumn{2}{|c|}{ FLT3-ITD Mutation } & 7 & 6 & I \\
\hline \multirow{7}{*}{ FAB Subtype } & MI & 4 & 4 & 0 \\
\hline & M2 & 52 & 38 & 14 \\
\hline & M3 & 20 & 16 & 4 \\
\hline & M4 & 14 & I & 13 \\
\hline & M5 & 3 & 3 & 3 \\
\hline & M6 & 2 & 2 & 0 \\
\hline & M7 & & & \\
\hline \multirow{4}{*}{$\operatorname{TLC}\left(\times 10^{9} / 1\right)$} & Less than 10 & 15 & 11 & 4 \\
\hline & $11-50$ & 39 & 26 & 13 \\
\hline & $51-100$ & 41 & 24 & 17 \\
\hline & More than 100 & - & & \\
\hline \multirow{4}{*}{$\begin{array}{l}P \text { I a t e I e } t \\
\text { count }\left(\times 10^{9} / 1\right)\end{array}$} & Less than 10 & 5 & 3 & 2 \\
\hline & $11-50$ & 33 & 23 & 10 \\
\hline & $51-100$ & 50 & 31 & 19 \\
\hline & More than 100 & 7 & 4 & 3 \\
\hline
\end{tabular}


Table 3 FAB subtype of Acute Myeloid leukemia diagnosed at AFIP from September 2014 to June 20 I5 and their percentage positivity for NPMI gene mutation

\begin{tabular}{llll}
\hline FAB subtype & Number of patients & NPMI gene mutation positive cases & Percentage positivity \\
\hline AML M2 & 52 & 14 & $26.90 \%$ \\
AML M4 & 14 & 13 & $92.80 \%$ \\
AML M5a & 3 & 3 & $100 \%$ \\
AML M3 & 20 & 3 & $14.20 \%$ \\
\hline
\end{tabular}

Mean age of NPM1 mutation positive patients was 47.5 years. Patients of age between 5 to 85 years were considered in the study. The incidence of mutation was significantly associated with a high TLC with a mean TLC of $49.0 \times 10^{9} / 1$ in positive cases (Range $2-97 \times 10^{9} / 1$ ). Platelet count in the positive cases was relatively preserved with a mean platelet count of $67.2 \times 10^{9} / 1$ (Range $6-119 \times 10^{9} / 1$ ).

Out of 34 NPM1 positive patients 14 patients were AML M2 subtype, 13 patients were AML M4, 3 cases were AML M3 while there were 3 cases of AML M5a.

\section{Discussion}

Acute myeloid leukemia (AML) develops from malignant transformation of immature hematopoietic cells through a complex multistep process that requires cooperation of different types of genetic alterations. ${ }^{13}$ Alterations associated with AML include recurrent fusion genes such as $\mathrm{t}(8 ; 21)$, inv(16), and $\mathrm{t}(15 ; 17)$ that affect transcription factors or components of the transcriptional co-activation complex, resulting in impaired differentiation and/or aberrant self-renewal capacity by hematopoietic progenitors. In addition to these, a group that comprises mutation in genes involved in the proliferation and survival potential of hematopoietic progenitors includes receptor tyrosine kinases (FLT3, KIT, and RAS), oncogenic transcription factor (CEBP/alpha), and Nucleophosmin (NPM1) mutation. Many of these gene mutations figure importantly as a provisional clinico pathologic entity in the revised World Health Organization (WHO) 2008 classification of myeloid neoplasms. ${ }^{14}$

The NPM1 mutation is the most frequent molecular abnormality seen in patients with AML and normal karyotype. It should be emphasized that to date this mutation has not been reported in patients with $\mathrm{t}(15 ; 17), \mathrm{t}(8 ; 21)$, inv(16)/t(16;16), and 11q23 rearrangements. ${ }^{15}$

In this study, $35.7 \%$ of the patients had an NPM1 mutation ( $p$ value $=0.92$ ), and insertion of 4 base pairs was observed in all the mutant positive cases. This incidence is close to the percentage reported by other studies, $35 \%$ of adult cytogenetically normal AML. ${ }^{3}$ Studies reported that NPM1 gene mutation is significantly associated with increasing age. ${ }^{10}$ our study shows a mean age of 47 years in the NPM1 positive patients and was less prevalent in younger age group.

Some studies reported the association of NPM1 mutation with female AML patients compared to males. ${ }^{7}$ in our study percentage of NPM1 mutation was higher in females $87.5 \%$ as compared to $50.9 \%$ in male AML patients showing an association of NPM1 mutation with female gender.

Some studies have reported that NPM1 mutation is associated with a high TLC and platelet count ${ }^{10}$ we found the association of NPM1 positivity with a high TLC only with a mean count of $49.0 \times 10^{9} / 1$. The platelet count in the NPM1 positive patients was relatively preserved but was not high.

Falini et al. ${ }^{8}$ mentioned significant association of NPM1 mutation with AML FAB M4 and M5 subtypes. In our study during this duration 52 AML M2 patients were diagnosed at AFIP and out of them 14 (26.9\%) were positive for NPM1 mutation. 20 cases were of AML M3, of them only 03 (14.2\%) were positive for NPM1 mutation. 13 out of 14 patients of AML M4 were positive for NPM1 gene mutation showing a percentage positivity of $92.8 \%$ while 03 cases of AML M5 presented at AFIP and of them all 3(100\%) were positive for the mutation showing association of NPM1 gene mutation with Monoblastic leukemia.

We followed up our NPM1 gene mutation positive cases after the Induction therapy with Injection Daunoblastine: 45 to $90 \mathrm{mg} / \mathrm{m}^{2}$ (Day 1 to Day 3) and Injection Cytosar: $100-200 \mathrm{mg} / \mathrm{m}^{2}$ (Day 1 to Day 7) dose adjusted according to Body surface area, Performance status and clinical condition. The results were as follows: $27(79.4 \%)$ out of 34 positive patients achieved their first complete remission, 5(14.7\%) patients expired before the commencement of the chemotherapy while $2(5.8 \%)$ expired during the induction phase. This is an ongoing study at our Institute and patients will be reviewed at 5 and 10 years period.

\section{Conclusion}

In conclusion, frequency of NPM1 (35.8\%) was high in patients of acute myeloid leukemia in present study. Detection of NPM1 gene mutations may allow dissection of the heterogeneous group of AML with normal karyotype into prognostically different subgroups. Exploring the mechanisms may lead to a better understanding of how mutant NPM protein becomes leukemogenic, thereby providing insights for the development of new chemotherapeutic agents.

\section{Acknowledgements}

None.

\section{Conflict of interest}

Author declares that there is no conflict of interest.

\section{References}

1. Ali A, Siddique MK, Shakoori AR. Frequency of NPM1 Mutations in Pakistani Acute Myeloid Leukemia Patients. Pakistan $J$ Zool. 2013;45(3):833-841.

2. Braoudaki M, Papathanassiou C, Katsibardi K, et al. The frequency of NPM1 mutations in childhood acute myeloid leukemia. J Hematol Oncol. 2010;3:41

3. Helbig G, Wozniczka K, Wieclawek A, et al. Clinical relevance of mutant NPM1 and CEBPA in patients with acute myeloid leukemia-preliminary report. Contemp Oncol (Pozn). 2014;18(4):241-245.

4. Falini B, Bolli N, Liso A, et al. Altered nucleophosmin transport in acute myeloid leukemia with mutated NPM1: molecular basis and clinical implications. Leukemia. 2009;23(10):1731-1743.

5. Ruan GR, Li JL, Qin YZ, et al. Nucleophosmin mutations in Chinese adults with acute myelogenous leukemia. Ann Hematol. 2009;88(2):159-166.

6. Falini B, Mecucci C, Tiacci E, et al. Cytoplasmic nucleophosmin in 
acute myelogenous leukemia with a normal karyotype. $N$ Engl $\mathrm{J} \mathrm{Med}$. 2005;352(3):254-266

7. Thiede C, Koch S, Creutzig E, et al. Prevalence and prognostic impact of NPM1 mutations in 1485 adult patients with acute myeloid leukemia (AML). Blood. 2006;107(10):4011-4020.

8. Falini B, Nicoletti I, Martelli MF, et al. Acute myeloid leukemia carrying cytoplasmic/mutated nucleophosmin (NPMc AML):biological and clinical features. Blood. 2007;109(3):874-885

9. Suzuki T, Kiyoi H, Ozeki K, et al. Clinical characteristics and prognostic implications of NPM1 mutations in acute myeloid leukemia. Blood. 2005;106(8):2854-2861.

10. Döhner K, Schlenk RF, Habdank M, et al. Mutant nucleophosmin (NPM1) predicts favorable prognosis in younger adults with acute myeloid leukemia and normal cytogenetics: interaction with other gene mutations. Blood. 2005;106(12):3740-3746.
11. Mori Y, Yoshimoto G, Kumano T, et al. Distinctive expression of myelomonocytic markers and down-regulation of CD34 in acute myelogenous leukaemia with FLT3 tandem duplication and Nucleophosmin mutation. Eur J Haematol. 2007;79(1):17-24.

12. Bolli N, Nicoletti I, De Marco MF, et al. Born to be exported: $\mathrm{COOH}-$ terminal nuclear export signals of different strength ensure cytoplasmic accumulation of Nucleophosmin leukemic mutants. Cancer Res. 2007;67(13):6230-6237.

13. Gilliland DG, Griffin JD. The roles of FLT3 in hematopoiesis and leukemia. Blood. 2002;100(5):1532-1542.

14. Vardiman JW, Thiele J, Arber DA, et al. The 2008 revision of the World Health Organization (WHO) classification of myeloid neoplasms and acute leukemia: rationale and important changes. Blood. 2009;114(5):937-951.

15. Boissel N, Renneville A, Biggio V, et al. Prevalence, clinical profile, and prognosis of NPM mutations in AML with normal karyotype. Blood. 2005;106(10):3618-3620. 